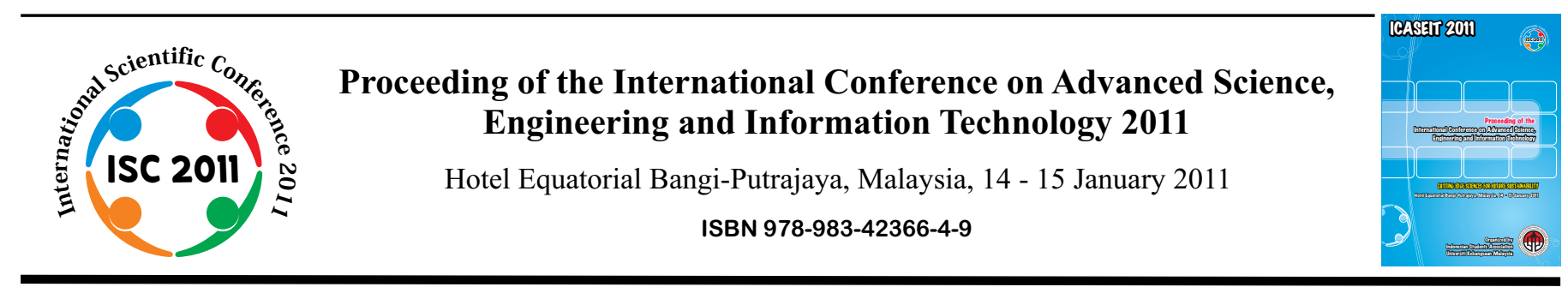

\title{
A Study on Benchmarking Models and Frameworks in Industrial SMEs: Challenges and Issues
}

\author{
Masoomeh Zeinalnezhad ${ }^{\#}$, Muriati Mukhtar ${ }^{*}$, Shahnorbanun Sahran ${ }^{\#}$ \\ \#*\# Department of Industrial Computing, Faculty of Science and Information Technology, National University of Malaysia \\ (UKM), 43600 UKM Bangi, Malaysia \\ ${ }^{\#}$ Tel.:+60147313738, E-mail: m.zeinalnezhad@gmail.com \\ *Tel.:+60389216732, E-mail: mm@ftsm.ukm.my \\ ${ }^{\#}$ Tel.:+60389215555, E-mail: shah@ftsm.ukm.my
}

\begin{abstract}
This paper is based on a literature review of recent publications in the field of benchmarking methodology implemented in small and medium enterprises with regards to measure and benchmark upstream, leading or developmental aspects of organizations. Benchmarking has been recognized as an essential tool for continuous improvement and competitiveness. It can also help SMEs to improve their operational and financial performances. However, only few entrepreneurs turn to benchmarking implementation, due to lack of time and resources. In this study current benchmarking models (2005 onwards), dedicated specifically to the SMEs, have been identified and their characteristics and objectives have been discussed. Key findings from this review confirm that this is an under-developed area of research and that most practitioner approaches are focused on benchmarking practices within SMEs. There is a need to extend theoretical and practical aspects of benchmarking in SMEs by studying the process of benchmarking with regards to the novel concept of lead benchmarking as a possible means of achieving increased radical and innovative transformation in organizational change. From the review it emerged that, lead, forward looking and predictive benchmarking have not been considered in SMEs, and future researches could include them.
\end{abstract}

Keywords — Industry, Benchmarking, Manufacturing, Small and Medium Enterprises (SMEs), Innovation.

\section{INTRODUCTION}

Recent global changes have forced manufacturing organizations across the globe to reconsider their management techniques and tools. One of the most practical management tools is benchmarking, that since its appearance in the 1980s, it has been a popular management concept and its value as a practical tool for developing critical areas of a business is indisputable [1]. In recent years, many organizations have discovered the value of benchmarking and are applying it to improve their processes and their systems [2]. Also, to compete in the globalized and turbulent markets, SMEs have to benchmark themselves with the best in industry [3]. Starting from a review of the recommendations provided in literature regarding applicable of benchmarking in companies, this paper aims to highlight requirements for developing a comprehensive benchmarking model dedicated specially to SMEs environment. To develop a good tool for SMEs, it is necessary to start from a detailed analysis of SME needs [12].
Following this introductory section, next section presents the literature review and includes a review of theory, assumptions, advantages, limitations, and work that had been done by other researches in the area of application of benchmarking in small and medium enterprises. In this section, after defining the term of SME, characteristics and challenges of SMEs, their importance in the economies and their challenges will be investigated. Then, the role of benchmarking implementation in SMEs will be described briefly. The rest of this paper is devoted to presenting an overview of benchmarking models and frameworks implemented in SMEs. Conclusions indicate that there is a need, and further scope, to develop a knowledge-based benchmarking approach for small to medium firms.

\section{SME DEFINITION}

SME refers to small and medium size enterprise. There are a number of definitions of what constitutes an SME ([4], [5], [6]). Definitions of SMEs vary between countries ([7], 
[8]) with some using the number of members and others, business capital.

Finding of research launched by Rahman [9] defined SMEs by a number of factors and criteria, such as location, size, age, structure, organization, number of employees, sales volume, worth of assets, ownership through innovation and technology.

Sometimes definitions are based on quantitative measures such as staffing levels, turnover or assets, while they employ a qualitative approach.

In keeping with definitions developed in the literature, Jafari et al. [5] offered SMEs can be classified into four different types, according to the structure of the market, where they are located, to the prevalent innovation rate, and to their organization. On the other hand, SMEs can be organized as production cooperatives (clusters), or in networks under the dominance of a large firm.

Many countries have their own definition of what constitutes as SME. For example, according to The United States Census Bureau [10], small companies have no more than 500 employees, medium companies consist of 500 to 2499 employees, and large companies have more than 2500 employees. Whereas, Australian Bureau of Statistics [11] defined small businesses include sole proprietorships and partnerships without employees, businesses employing fewer than five people as micro-businesses and other businesses employing five or more people but less than 20 people as small ones, while medium-sized businesses were those employing fewer than 200 people.

\section{SME CHARACTERISTICS AND CHALLENGES}

Although numbers are broadly used to identify whether a company is a SME or not, this should be complemented by a set of characteristics which enable a better definition of the term "SME" [12]. Small and medium enterprises are regarded as one of the main driving forces of economic development, stimulating private ownership and entrepreneurial skills [13], as they are crucial for sustained, long-term growth, dynamism and employment [7].SMEs generally employ the largest percentage of the workforce and are responsible for income generation opportunities [14]. For example, SMEs in Australia employ nearly 49 per cent of all private sector employees [15], in the European Union, SMEs contributing to two-thirds of all employment [16] and Greek SMEs employ 74 per cent of the private-sector labour force. SMEs can be rich sources of innovation in relation to new management methods. Smaller companies are leaner and show a more decentralized production structure and they are able to introduce new products faster to the market [17]. Majority of SMEs have simple systems and procedures, which allows flexibility, immediate feedback, short decisionmaking chain, better understanding and quicker response to customer needs than larger organizations [3]. However, all the authors highlight scarcity of resources as one of the main problems and typical characteristic of SMEs [3]. The term "resources" is considered both in terms of personnel, including also managerial time, and financial stability and security. In addition skills are limited, not only among staff [3], but also owner-managers often do not have enough managerial expertise or organizational capabilities and this implies poor strategic business planning and human resource management [18]. Furthermore, SMEs operate in highly competitive, turbulent and uncertain markets [19] and they do not have control or influence over the market. In addition, Singh et al. [14] concluded that hurdles for the competitiveness of SMEs, include: a lack of effective selling techniques and limited market research, excessive costs of product development projects, inability to meet the demand for multiple technological competencies, information gaps between marketing and production functions, lack of funds for implementing suitable software, a shortage of management talent, weak intellectual property protection, underdeveloped technology transfer systems and lack of stability in the regulatory environment [14].

\section{IMPLEMENTATION OF BENCHMARKING METHODOLOGY IN SMES}

Benchmarking is "a management tool that can be defined as the systematic process of searching for best practices, innovative ideas and efficiencies that lead to continuous improvement" [20]. Despite the fact that benchmarking is well known in the business environment, especially among large companies [21], it is not much known or used by SMEs ([22], [23]). This observation is supported by extensive research conducting by Massa and Testa [24]. These authors stated that benchmarking is generally both expensive and time consuming: a firm (especially an SME) usually does not have enough resources to start a benchmarking project. Probably the real problem posed by benchmarking in SMEs is the lack of understanding of what this technique really is, due to the amount of approaches in use, and variety of interpretations of what the term 'benchmarking' actually means [23]. Cassell et al. [22] pointed out that few entrepreneurs turn to benchmarking, giving the lack of time as an excuse, resources, and even relevance, whereas those who have used benchmarking recognize its effectiveness and its usefulness for their organization. But, for continuous improvement and change, SMEs have to benchmark themselves with the best in the industry [3]. Furthermore, distinct strategic objectives, greater environmental uncertainty and limited resources are some of the aspects that would require the development of benchmarking practices that are specific to SMEs if these practices are to be adopted effectively [25].

Benchmarking allows the SMEs to improve their operational and financial performance thus confirming the usefulness of benchmarking for SMEs, especially since traditional performance models for large enterprises do not apply well to SMEs [25]. They have greater potential than large companies to benefit from benchmarking but often the techniques required are unknown or inaccessible to them, or at least perceived as such. In this perspective, it is extremely important to provide SMEs with adequate tools and methodologies able to support the development of management systems [19].

Various studies indicate that theories and practices developed for larger organizations may not be suitable for SMEs ([22], [23], [25]-[27]). Cassell et al. [22] emphasized that benchmarking activities developed for SMEs must be specific to the environment and constraints of these organizations if the implementation of the practices identified by such activities is to succeed and result in 
increased performance. Moreover, there is a need to extend theoretical and practical aspects of benchmarking in SMEs by studying the process of benchmarking, not only its achieved results [23]. Considering the rapid changes in the competitive era, SMEs should adapt themselves with the harmony of change [5], then to compete successfully in the domestic and global markets, they are encouraged to capitalize on outward investment opportunities, adopt best business practices and be more resilient in the face of greater competition. For an in-depth understanding of these issues the reader is referred to [28].

\section{Current Benchmarking Models}

The literature provides some examples of tools and frameworks for benchmarking. Based on the review of current publications on benchmarking, it was found that from 2005 onwards there are about thirty six benchmarking models and tools and nine of them are developed especially for SMEs. These models could guide and assist SMEs throughout the benchmarking implementation process. These frameworks and methods are given in Table 1.

To this end Wainwright et al. [34] developed a contingency framework for reviewing benchmarking and ICT simultaneously, in terms of using for comparing practice and performance with respect to ICT within small firms. They have found those ICT benchmarking tools that were available, mostly focused on the detail, scale, scope, integration and availability of ICT.

On the basis of empirical data, Ochoa-Laburu et al. [33] introduced a benchmarking tool called "QuickView" to help small and medium size manufacturing companies better understand the problems and opportunities confronting their operations. They demonstrated that QuickView is a valid tool to use on non-US SMEs to help build local databases containing local companies.

Another method for benchmarking on managerial practices has been proposed by Garengo et al. [19]. On the basis of literature review and empirical research, they have gathered further information by means of workshops and interviews to experts and developed their tool into five stages: preliminary analysis, defining the model, developing the tool, testing and refinement and diffusion. They indicated that testing and diffusing of the tool had had very positive results.

Deros et al. [4] on the basis of empirical data and an analysis previous maturity models, suggested a conceptual framework for benchmarking implementation dedicated to the automotive manufacturing SMEs. In their study with comparing the characteristics of SMEs and large organizations, they have divided the differences of SMEs into four categories: structure, systems and procedures, culture and behavior, human resources, and also market and customers.

A computerized benchmarking tool, called "PDG: a bird's eye view", was designed by St-Pierre and Delisle [25] to evaluate a SME, from an external perspective and on a comparative basis, in order to produce a diagnosis of its performance and potential, complemented with relevant recommendations. The research results with hundreds of SMEs showed that benchmarking allowed SMEs to improve their operational performances.
Maire et al. [32] proposed a set of tools and methods especially targeted at: 1) the description of the processes (process to be improved and reference process) using the description of the current practices used (Observe step); and 2 ) the comparison of these processes, leading to suggestions of improvements to carry out on the process to improve (Analyze step). They indicated that the steps of the planresearch-observe-analyzes-adapt-improve cycle are mostly reserved for big companies, therefore detailed observe and analyze steps should add as a set of tools and methods to assist SMEs in the deployment of the steps of a benchmarking process.

Another tool has been proposed by Carpinetti and Oiko [21], on the basis of case study as the field research methodology for theory testing and refinement. According to their approach, a benchmarking information system designed for use within a cluster comprises two parts: the database itself and a web application for remote access to the database, which was developed, respectively, in SQL Server and Active Server Pages. They believed that the adoption of the concepts and practices of benchmarking to carry out joint actions among companies of a cluster can aid to consolidate cooperation, linkages and information exchange among companies as well as develop a culture of continuous innovation, thus contributing to the development of the collective efficiency of the cluster.

However, the problem highlighted, indicate that these tools and models still suffer from weaknesses that need improvements, which suit to SMEs' structures, processes, resources and culture especially to achieve increased radical and innovative transformation in organizations. Therefore there appears to be a gap in literature regarding practical improvement tools that can support SMEs in the process of identifying the main weaknesses of their performances.

As had been discussed before, SMEs faced with lack of knowledge and expertise, thus a framework that provide a comprehensive and overall view could help and guide them through all the stages of the benchmarking implementation effort [4]. The currency of benchmarking and performance measurement needs a radical and indeed innovative transformation to adhere to the dynamics of the business environment [29] as, upstream, leading or developmental aspects of organizations should be measured and benchmarked [30]. To achieve increased organizational change, Anderson and McAdam ([29], [31]) have defined lead benchmarking concept as benchmarking and performance measurement, which focuses on analyzing forward looking, predictive and future performance comparisons. The results of their researches indicate that larger organizations were more likely to strategically implement and make effective use of lead benchmarking and performance measures in comparison to smaller organizations. In particular, larger organizations placed a more upstream emphasis on the initiative than that of smaller organizations, because of, first, larger organizations have more resources and skills than smaller organizations in relation to experimenting with lead benchmarking and performance measures; secondly, and related to the first point, small organizations traditionally lag behind larger organizations in implementing new initiatives due to the innate bias in the literature that suggests large private sector 
organizations try it first and then public and small sector organizations come second. However, there is no specific reason that does not allow smaller organizations from adopting lead benchmarking and performance measurement approaches suited to their resource and skills capabilities [31]. As shown in the Fig. 1, the conceptual model illustrates the different important elements of lead benchmarking. Lead benchmarking extends beyond internal and external performance measures to incorporate lead and lag measures of performance ([29], [31]).

\section{CONCLUSION AND FUTURE WORKS}

The paper described the evolution of benchmarking methods and tools that SMEs have used to evaluate and improve their performance. This review of the literature, examining the domains of benchmarking for business excellence, small firms, academic and practitioner approaches to benchmarking, highlights that benchmarking provides essentially the capacity of effective organizational learning, improved organizational performance and enhanced capability for innovation. Since SMEs require benchmarking models specifically designed and tailored on their own characteristics and needs, SME characteristics and current benchmarking practices have been reviewed and analyzed to derive the main characteristics of an effective benchmarking framework for a SME. From the review it emerged that many SMEs have a number of general characteristics: 1) they operate in highly competitive, turbulent and uncertain markets, 2) they do not have control or influence over the market and thus they need to adopt a reactive approach and adapt to market changes, 3 ) they are usually closer to the customers and have the possibility to develop more personal relationships with them, 4) SMEs' demand is made by stronger customers throughout the supply chain and this implies difficulties in leveraging payments of debts and consequently in coping with fluctuations in cash flow, causing a lack of control over the future, 5) they have scarcity of resources in terms of financial stability and security and skills, not only among staff, but also owner-managers often do not have enough managerial expertise or organizational capabilities, 6) they have flat organizational structure with lack of bureaucracy that leads to flexibility, adaptability and rapidity in responding to the changing environment, 7) In SMEs, managers very often are also the owners of the company and organizational success or failure in SMEs is seriously affected by the managerial competencies of the ownermanager rather than on analysis of information.



Fig. 1 Initial conceptual model of lead benchmarking (adopted from [30]) 


\begin{tabular}{|c|c|c|c|c|c|}
\hline & Author(s) & Year & Ref. & Objectives & Explanation \\
\hline 1 & $\begin{array}{l}\text { Cocca \& } \\
\text { Alberti }\end{array}$ & 2010 & [13] & $\begin{array}{l}\text { To develop a framework that SMEs can use } \\
\text { to assess their performance measurement } \\
\text { system in order to identify the main } \\
\text { weaknesses and take corrective measures. }\end{array}$ & $\begin{array}{l}\text { The proposed tool codifies best practices and makes } \\
\text { them accessible by SMEs in a simple way, thus } \\
\text { supporting companies in the process of continuous } \\
\text { improvement of their performance measurement } \\
\text { system. }\end{array}$ \\
\hline 2 & $\begin{array}{l}\text { Singh et } \\
\text { al. }\end{array}$ & 2008 & [3] & $\begin{array}{l}\text { To identify the major areas of strategy } \\
\text { development by SMEs for improving } \\
\text { competitiveness of SMEs in globalised } \\
\text { market. }\end{array}$ & $\begin{array}{l}\text { This is a general review that explores major areas for } \\
\text { research on SMEs. }\end{array}$ \\
\hline 3 & $\begin{array}{l}\text { Carpinetti } \\
\& \text { Oiko }\end{array}$ & 2008 & [21] & $\begin{array}{l}\text { Development and application of a } \\
\text { benchmarking information system designed } \\
\text { for use within a cluster of SMEs. }\end{array}$ & $\begin{array}{l}\text { The paper proposes to apply the concepts and } \\
\text { techniques of business performance management and } \\
\text { improvement to manage performance of clusters of } \\
\text { companies, offering a new approach on how to } \\
\text { improve the collective efficiency of a cluster. }\end{array}$ \\
\hline 4 & $\begin{array}{l}\text { Maire et } \\
\text { al. }\end{array}$ & 2008 & {$[32]$} & $\begin{array}{l}\text { Setting tools and methods to assist SMEs in } \\
\text { the deployment of the steps of a } \\
\text { benchmarking process (plan-research- } \\
\text { observe-analyzes-adapt-improve cycle). }\end{array}$ & $\begin{array}{l}\text { The proposed methods and tools have been applied in } \\
\text { several manufacturing plants at TECUMSEH Europe } \\
\text { and practically help to a SME to carry out a } \\
\text { benchmarking. }\end{array}$ \\
\hline 5 & $\begin{array}{l}\text { St-Pierre } \\
\& \text { Delisle }\end{array}$ & 2006 & [25] & $\begin{array}{l}\text { To present a fully implemented expert } \\
\text { diagnostic system which evaluates on a } \\
\text { benchmarking basis the performance of } \\
\text { SMEs. }\end{array}$ & $\begin{array}{l}\text { The paper highlights the development and use of a } \\
\text { benchmarking-based " } 360 \text {-degrees" performance } \\
\text { evaluation system for SMEs and shows that } \\
\text { benchmarking allows them to improve their } \\
\text { operational and financial performance thus } \\
\text { confirming the usefulness of benchmarking for } \\
\text { SMEs, especially since traditional performance } \\
\text { models for large enterprises do not apply well to } \\
\text { SMEs. }\end{array}$ \\
\hline 6 & $\begin{array}{l}\text { Deros et } \\
\text { al. }\end{array}$ & 2006 & {$[4]$} & $\begin{array}{l}\text { To present a conceptual framework for } \\
\text { benchmarking implementation in SMEs } \\
\text { taking into consideration their characteristics. }\end{array}$ & $\begin{array}{l}\text { This guidance and framework provides a useful guide } \\
\text { for companies to adopt and adapt before embarking } \\
\text { on their benchmarking journey. }\end{array}$ \\
\hline 7 & $\begin{array}{l}\text { Garengo } \\
\text { et al. }\end{array}$ & 2005 & [19] & $\begin{array}{l}\text { Development a tool for synthetic } \\
\text { benchmarking on managerial practices which } \\
\text { can support the qualitative growth of SMEs. }\end{array}$ & $\begin{array}{l}\text { The tool is able to allow SMEs to learn best } \\
\text { managerial practices, assess itself with respect to } \\
\text { these practices and at the same time understand what } \\
\text { must be done to carry out improvement. }\end{array}$ \\
\hline 8 & $\begin{array}{l}\text { Ochoa- } \\
\text { Laburu et } \\
\text { al. }\end{array}$ & 2005 & [33] & $\begin{array}{l}\text { Cross-national evaluation and benchmarking } \\
\text { of manufacturing SMEs using an expert } \\
\text { system based assessment tool (QuickView) } \\
\text { already in use in the USA. }\end{array}$ & $\begin{array}{l}\text { The research proves that QuickView is a valid tool to } \\
\text { use on non-US SMEs to help build local databases } \\
\text { containing local companies. }\end{array}$ \\
\hline 9 & $\begin{array}{l}\text { Wainwrig } \\
\text { ht et al. }\end{array}$ & 2005 & [34] & $\begin{array}{l}\text { To provide a review and critique of the } \\
\text { benchmarking literature with respect to } \\
\text { information and communication technology } \\
\text { (ICT) adoption and usage within small firms } \\
\text { that was used as the basis for developing a } \\
\text { framework for benchmarking ICT practice, } \\
\text { competence and performance in small firms }\end{array}$ & $\begin{array}{l}\text { This research paper highlighted that there could be a } \\
\text { direct link between adoption and use of the } \\
\text { benchmarking tool and improved ICT performance. } \\
\text { Little focus is placed on the human skills, knowledge } \\
\text { and competences concerning ICT both for ICT } \\
\text { specialists, business personnel with some degree of } \\
\text { ICT role or managers who must align IT within the } \\
\text { business strategy and effect process and } \\
\text { organizational change.. }\end{array}$ \\
\hline
\end{tabular}


In order to adapt to the rapidly changing and highly competitive business environment, different means proposed in literature for benchmarking methods especially dedicated to a SME context have been considered and discussed. All the tools and frameworks for benchmarking provided by the literature and described above do not make explicit reference to the size of the target companies; furthermore, some of them are too complex and resource intensive to be used effectively in a SME context. There appears to be a gap in literature regarding practical benchmarking models that can support SMEs in the process of identifying the main weaknesses of their performances and continues improvement. This will provide insight into SME needs, capability to adopt innovations, and training requirements. It could be concluded that there is a need for studies that attempt to measure and benchmark upstream, leading or developmental aspects of organizations.

\section{REFERENCES}

[1] G. Anand, and R. Kodali, "Benchmarking the benchmarking models", Benchmarking: An International Journal, vol. 15, no. 3, pp. 257-291, 2008.

[2] R. Manzini and V. Lazzarotti, "The benchmarking of information systems supporting the university administrative activities", Benchmarking: An International Journal, vol. 13, no. 5, pp. 596-618, 2006.

[3] R.K. Singh, S.K. Garg and S.G. Deshmukh, "Strategy development by SMEs for competitiveness: a review", Benchmarking; An International Journal, vol. 15, no. 5, pp. 525-547, 2008.

[4] B.M. Deros, S.M. Yusof and A.M. Salleh, "A benchmarking implementation framework for automotive manufacturing SMEs", Benchmarking: An International Journal, vol. 13, no.4, pp. 396-430, 2006

[5] M. Jafari, M. Fathian, P. Akhavan and R. Hosnavi, "Exploring KM features and learning in Iranian SMEs", VINE: The journal of information and knowledge management systems, vol. 37, no. 2, pp. 207-218, 2007.

[6] M. Fathian, P. Akhavan and M. Hoorali, "E-readiness assessment of non-profit ICT SMEs in a developing country: The case of Iran", Technovation, vol. 28 no. 9, pp.578-590, 2008.

[7] K. Thassanabanjong, P. Miller and P. Marchant, "Training in Thai SMEs", Journal of Small Business and Enterprise Development, vol. 16 no. 9, pp. 678-693, 2009.

[8] S.M. Mirbargkar, "Global Competitiveness: Iranian SME", SCMS Journal of Indian Management, October - December, 2009.

[9] S. Rahman, "A comparative study of TQM practice and organizational performance of SMEs with and without ISO 9000 certification", International Journal of Quality \& Reliability Management, vol. 18 no.1, pp.35-49, 2001.

[10] U.S. Census Bureau (2008), "Statistics about Business Size (including Small Business) from the U.S. Census Bureau," available at: http://www.census.gov/epcd/www/smallbus.html.

[11] Australian Bureau of Statistics (ABS), Small Business in Australia, Catalogue No. 1321.0, Canberra, (2001).

[12] P. Cocca and M. Alberti, "A framework to assess performance measurement systems in SMEs", International Journal of Productivity and Performance Management, vol. 59 no. 2, pp. 186200, 2010.

[13] D. Gadenne and B. Sharma, "An investigation of the hard and soft quality management factors of Australian SMEs and their association with firm performance", International Journal of Quality \& Reliability Management, vol. 26 no. 9, pp. 865-880, 2009.

[14] R.K. Singh, S.K. Garg and S.G. Deshmukh, "The competitiveness of SMEs in a globalized economy Observations from China and India", Management Research Review, vol. 33 no.1, pp. 54-65, 2010.

[15] Australian Bureau of Statistics (ABS), Counts of Australian Business Operators, 2006 to 2007, Catalogue No. 8175.0, Canberra, (2008).
[16] E.G. Carayannis, D. Popescu, C. Sipp and M. Stewart, "Technological learning for entrepreneurial development (TL4ED) in the knowledge economy (KE): case studies and lessons learned", Technovation, vol. 26 no.4, pp.419-43, 2006.

[17] B. Denkena, R. Apitz and C. Liedtke, "Knowledge-based benchmarking of production performance", Benchmarking: An International Journal, vol. 13 no. 1/2, pp. 190-199, 2006.

[18] J. Pansiri and Z.T. Temtime, "Assessing managerial skills in SMEs for capacity building", Journal of Management Development, vol. 27 no.2, pp.251-60, 2008.

[19] P. Garengo, S. biazzo, A. Simonetti and G. Bernardi, "Benchmarking on managerial practices: a tool for SMEs", The TQM Magazine, vol. 17 no. 5 , pp.440-455, 2005.

[20] W.P. Wong and K.Y. Wong, "A review on benchmarking of supply chain performance measures", Benchmarking: An International Journal, vol. 15 no. 1, pp. 25-51, 2008.

[21] L.C.R. Carpinetti and O.T. Oiko, "Development and application of a benchmarking information system in clusters of SMEs", Benchmarking: An International Journal, vol. 15 no. 3, pp. 292-306, 2008.

[22] C. Cassell, S. Nadin and M.O. Gray, "The use and effectiveness of benchmarking in SMEs", Benchmarking: An International Journal, vol. 8 no. 3, pp. 212-22, 2001.

[23] R.R.S. Bernard, "The benchmarking process: empirical evidences from small and medium-sized enterprises", An unpublished $\mathrm{PhD}$ thesis, University of Montreal, Canada, 2005.

[24] S. Massa and S. Testa, "Innovation or imitation? Benchmarking: a knowledge-management process to innovate services", Benchmarking: An International Journal, vol. 11 no. 6, pp. 610-620, 2004.

[25] J. St-Pierre and S. Delisle, "An expert diagnosis system for the benchmarking of SMEs' performances", Benchmarking: An International Journal, vol. 13 no. 1/2, pp. 106-119, 2006.

[26] G. Premkumar, "A meta-analysis of research on information technology implementation in small business", Journal of Organizational Computing and Electronic Commerce, vol. 13 no. 2, pp. 91-121,2003.

[27] S. Bruque and J. Moyano, "Organizational determinants of information technology adoption and implementation in SMEs: the case of family and cooperative firms", Technovation, vol. 27 no. 5, pp. 241-53, 2007.

[28] M. Zeinalnezhad, M. Muriati, S. Shahnorbanun, S and T. Pourrostam, "Benchmarking, Benchlearning and Innovation, A literature Review and a Research Agenda", The paper presented at The 2010 International Conference on Innovation and Management, Penang, Malaysia, paper ID:0222, 2010.

[29] K. Anderson and R. McAadm, "A critique of benchmarking and performance measurement", Benchmarking: An International Journal, vol. 11 no. 5, pp. 465-483, 2004.

[30] R. McAdam, S. Hazlett and K. Anderson-Gillespie, "Developing a conceptual model of lead performance measurement and benchmarking", International Journal of Operations \& Production Management, vol. 28 no. 12, pp. 1153-1185, 2008.

[31] K. Anderson and R. McAdam, "An empirical analysis of lead benchmarking and performance measurement", International Journal of Quality \& Reliability Management, vol. 22 no. 4, pp. 354-375, 2005 .

[32] J. Maire, V. Bronet and M. Pillet, "Benchmarking: methods and tools for SME", Benchmarking: An International Journal, vol. 15 no. 6, pp. 765-781, 2008.

[33] C. Ochoa-Laburu, G.R. Simons and R. Trachtenberg, "Cross-national evaluation and benchmarking of manufacturing SMEs using an expert system based assessment tool (QuickView)", Benchmarking: An International Journal, vol. 12 no. 1, pp. 16-29, 2005.

[34] D. Wainwright, G. Green, E. Mitchell and D. Yarrow, "Towards a framework for benchmarking ICT practice, competence and performance in small firms", Performance Measurement and Metrics: The International Journal for Library and Information Services, vol. 6 no. 1, pp. 39-52, 2005. 